\title{
FUENTES
}

\section{Libretas inéditas de Juana Fernández Solar Santa Teresa de Jesús de los Andes}

\section{Presentación}

En el contexto del centenario de santa Teresa de Jesús de los Andes, que se celebra el 12 de abril de 2021, en conjunto con la comunidad del Monasterio de carmelitas descalzas del Espíritu Santo de Auco, Los Andes, la revista Teología y Vida ofrece la publicación de las libretas inéditas de la santa carmelita. El autógrafo de estas libretas se conserva en el Monasterio de Auco, junto con el resto de los textos originales de la santa. De acuerdo a la numeración del archivo del monasterio, se trata de las libretas 5 (1914), 6 (1915), 4 (1917), 7 (1917), un texto de 1919 y la libreta 1 (1919-1920).

Estas libretas inéditas son valiosas por diferentes motivos. Los escritos más tempranos, contenidos en las libretas 5 y 6 , redactados en 1914 y 1915, son los apuntes tomados por Juana -a los 13 y 14 años de edad- de las meditaciones del predicador de los retiros. Por lo mismo, permiten conocer aspectos de la formación religiosa que recibió la santa, pero no reflejan directamente su propia espiritualidad, sino más bien la de los padres predicadores. Buena parte del contenido de estos apuntes es un reflejo de la religiosidad y de los prejuicios culturales de inicios del siglo Xx. Por este motivo, la comparación y, más aún, el contraste entre el contenido de estos apuntes y los escritos posteriores de Teresa de los Andes ofrece al lector atento interesantes elementos para reconocer los rasgos más característicos de la espiritualidad que, como es lógico, está inserta en su época y está expresada en su lenguaje. En síntesis, estos tempranos apuntes de retiro, que reflejan la religiosidad que ella recibió en el colegio del Sagrado Corazón, ayudan a distinguir lo que es propio de santa Teresita respecto de la formación religiosa que recibió de niña. Los escritos 
posteriores, a saber, las libretas 4, 7, un texto escrito poco antes de entrar al Carmelo y la libreta 1 son más personales y, por ello, reflejan mejor la espiritualidad propia de la santa. La libreta 4 contiene unos pensamientos sobre el sufrimiento, redactados en 1917; la libreta 7 ofrece un escrito del mismo año 1917 que consiste en una meditación de preparación a la comunión y otra para después de comulgar; luego, se publica un texto que no pertenece a las libretas, sino a un breve documento que, según una anotación de Elisa Valdés, fue escrito por Juana Fernández poco antes de entrar al Carmelo, es decir, a inicios de 1919; finalmente, la libreta 1 transmite un amplio examen de conciencia que, de acuerdo a la clasificación del archivo, fue redactado entre los años 1919 y 1920, es decir, cuando ya estaba en el Carmelo.

Entre estos escritos, se destaca la libreta 7 , que contiene unas reflexiones sobre la comunión eucarística. Estas meditaciones poseen un gran valor porque ponen al lector en contacto directo con la piedad eucarística de Teresita. Este texto no refleja las palabras de los predicadores de retiros, como las libretas 5 y 6 , sino la propia espiritualidad de la santa.

La presente edición se basa en la transcripción realizada por la comunidad del Monasterio de carmelitas descalzas del Espíritu Santo de Auco, Los Andes. Luego, en su corrección, han participado Blanca Besa y Franco Rojas. De acuerdo a la naturaleza de este tipo de documentos, los escritos han sido transcritos de manera literal y se ha buscado intervenir los textos lo menos posible. Sin embargo, para ofrecer un texto legible, ha sido necesario reconstruir la puntuación, corregir algún error de escritura y realizar un par de trasposiciones y de integraciones de mínima entidad. La escritura, en general, es legible, y sólo en pocos lugares la transcripción es conjetural.

La presente publicación ofrece a los estudiosos y al público en general un conjunto de textos, hasta ahora, inéditos de la primera santa chilena. Después de estos escritos, sólo falta por publicar algunas páginas contenidas en unos cuadernos que actualmente se conservan en el archivo del Monasterio del Espíritu Santo de Auco.

SAMUEL FERNÁNDEZ Facultad de Teología, Pontificia Universidad Católica de Chile sfernane@uc.cl 


\section{[RETIRO DE 1914] ${ }^{1}$}

\section{Meditación}

Vida. La llevaré al retiro y le hablaré a su corazón. ¿Para qué fuimos creados? Cuando nacemos oímos dos voces, una del ángel bueno y otro del ángel malo. ¿Cuál seguimos? Medios que el demonio se vale para quitar los frutos. Hemos de combatirlo con el respeto a la palabra de Dios y silencio.

\section{Plática}

Orad en todo momento y lugar y circunstancias. Son palabras del mismo Jesucristo: Cuando Jesucristo nació, todo lo que estaba ahí hablaba menos José y María que contemplaban a su hijo. Jesucristo hablaba oraba por nosotros. La oración o meditación es muy necesaria, y todos los hombres malos son así porque no meditan.

\section{Meditación}

Fin del hombre. Para qué fuimos creados. Para adorar y amar a Dios sobre todas las cosas.

\section{Meditación, II día}

De la confesión. No ha sido ningún hombre el que ha inventado este Sacramento, es Jesucristo, es Dios. Adán fue absuelto por Dios, les dio penitencia y los perdonó. A Moisés a Abrahán, ¿no fueron unos santos?, y no les dio la potestad de perdonar los pecados. Y solo Jesucristo, en el nuevo testamento, perdonaba los pecados. Los judíos se maravillaron que al paralítico le dijera: «Perdonados te son tus pecados» [Lc 5,20]. Los judíos admirados le dijeron: «Con qué poder perdonas los pecados, cuando Dios lo puede hacer» [Lc 5,21]. Jesucristo les dijo: «Qué me es [más] fácil decir, perdonados te son tus pecados o, anda toma tu camilla y vete a tu casa» [Lc 5,23-24]. Así lo hizo y los judíos se callaron.

Ej. Habiéndose presentado un gran pecador a un obispo, después de haberle dado la absolución, y el pecador lloraba mucho, para ver si era verdadera esa contrición [el obispo] le dijo: «Va [a] rezar tres Padrenuestros y Ave María, y después va [a] ayunar 3 días». El pecador le contestó: «¿Cómo, Señor?, yo que

\footnotetext{
${ }^{1}$ Libreta 5 (archivo del Monasterio de carmelitas descalzas del Espíritu Santo de Auco). Una mano que no es la de santa Teresa anota: «Resoluciones del Retiro de 1914 por el Padre Blasco (?). De edad de 13 años». Corresponde a los apuntes tomados en un retiro desde el lunes 27 hasta el miércoles 27 de abril de 1914. El domingo de resurrección, en 1914, fue el 12 de abril, por lo tanto, este retiro se realizó en el tiempo de Pascua.
} 
he pecado tanto y voy a ayunar tres días, eso es muy poco». Y se puso a llorar. El obispo le contestó: «Reza solamente un Padrenuestro y no ayuna». Se fue a rezarla, y tanto fue el pesar que murió. En la noche, se le apareció al obispo y le dijo: «Nuestro Señor ha permitido que pasase por el purgatorio y estoy en el cielo». Así se prueba cómo, sin el dolor y sin el propósito, no vale nada.

\section{Plática}

Sobre la conciencia. Hemos de procurar tener una consciencia recta, temerosa y tranquila. No hemos de pensar ni el pasado ni en lo futuro.

\section{Meditación}

Sobre la muerte. Imaginarse dos niñas, una feliz según el mundo, y la otra pobre. La última la vemos en un rancho abierto por los cuatro lados, y ella tendida entre pajas y sola. Se está muriendo. Ha sido rica, ha tenido muchas amigas y ha tenido padre, los hermanos la han abandonado y le han levantado una calumnia. Está pobre y muriéndose. Llega el confesor y ha hecho muchos actos. Espera el cielo. Imaginemos la otra, que está en un palacio rodeada de médicos y de sus padres. Llaman al confesor, no contesta, pero después se confiesa y se encuentra con las manos vacías. Y después, el sacerdote la absuelve, pero Jesucristo quien sabe si le dirá: «Yo te maldigo». Ahora otra, en París, una niña encantadora, la principiaron a pretender reyes príncipes, etc. Se principió a poner orgullosa. Después le llega la muerte y no hay un confesor, le dice a un criado que le abra un armario y le saca collares, perlas, pendientes, brillantes y toda la plata, y se la pone en la cama, y ella exclama: «iMaldita de mí, que amé las riquezas y no hice buenas obras, y ahora de qué me sirve todo esto!». ¿Qué muerte me gustaría tener?

\section{Plática}

\section{La Verdadera Piedad. Regularidad sin afectación.}

II. Reserva o moderación sin violencia. De Dios. Prójimos y de honestidad. Regularidad sin afectación, tener orden en las prácticas de piedad. Reserva y moderación sin grandes tristezas, pues la piedad debe ser alegre y ser moderada con las personas con quien tratamos y fijarnos. Y cuando oímos decir algo de Dios, si no se puede hacer concluir o defender, mostrarse como que no lo aprueba, y si no, interrumpir y defender. Unas dos niñas estaban en Valparaíso veraneando en otras familias, unos caballeros hablaron de Dios y de sus sacerdotes, la mayor se levanta de la mesa y dice: «Yo no puedo estar con gente maleducada», y se salió, y lo mismo hizo la otra, y se fueron a su pieza. Los caballeros les fueron a pedir excusas y ella le dijo: «No es a nosotras a quien debéis pedir dispensa sino a Dios, y cuando están delante de nosotras, no faltéis al respeto». Cuando se habla de nuestro prójimo, no meternos en la 
conversación, y cambiarla. Honestidad. No hablar nunca cosas deshonestas, porque dañan el alma, y nunca salen esas palabras. Una niña una vez se fue a confesar, y dijo al padre: «He dado la muerte». «¿Y por qué?», le contesto. «Porque un joven me iba a faltar el respeto, y yo le di una bofetada, y el joven cayó, y a los tres días murió». El padre le contestó que muy bien hecho. Y también tener cuidado con las sirvientes y no tener confianza con ellos.

\section{Meditación}

Sobre el Juicio. ¿Qué es el Juicio? Es una declaración completa del alma cuando sale de este mundo a Dios. Hay un ángel bueno y otro malo. Dice el Espíritu Santo que tanto va a ser $^{2}$ el rigor de Jesucristo como sus misericordias. Cuántas no ha hecho conmigo, murió por mí, derramó toda su sangre por salvarme, y cómo no va ser riguroso Jesucristo cuando su sangre fue perdida, despreciada su muerte. ¡Ay de mí, en este instante, no será mi Salvador sino un León furioso! Todos mis pensamientos, mis deseos, todo lo va [a] ver Dios como en un cristal puro, nada se va ocultar delante de sus ojos. ¡Ay, Jesús mío, tened piedad de mí que soy gran pecadora, y haced que yo muera contigo en mi corazón! ¡Ay, Jesús, no creo que serás mi Juez porque yo te haré prometer antes!

¡Oh, Madre mía!, tú estad cuando me esté juzgando tu Hijo, y haced que sea como un Hermano misericordioso, y que vea que, si yo lo he ofendido, ha sido por flaqueza y no con intención, y tú, Madre mía, tú, como Madre, defiéndeme, y mis pecados que son tan grandes excúsalos. ¡Oh Madre de mi corazón!, y tú eres mi amor, y desde hoy, Madre, por favor, socórreme y ponme en tu corazón; mira que el diablo inmundo me anda tentando. ¡Oh Madre mía, que vengan tentaciones, pero tú ayúdame, socórreme y haz que no sucumba! Y tú, después de mi Vida y de mi Todo, eres tú el amor de este corazón; pero haced que este amor sea puro como el tuyo, con el de mi Vida.

¡Oh José mío!, ¡oh Padre mío!, tú eres mi Amor, eres mi esperanza para la hora de mi muerte. ¡Oh Padre mío!, como mi linda Madre y como [mi] encantador Hermano te ayudaron a morir, así a mí también, que soy tu hija indigna, que te da desconsuelo a cada momento; pero, ¡oh Padre mío!, hasta hoy espero que mi Vida, mi Camino, mi Verdad, mi Hermano, mi Todo, mi amor, mi Madre, mi guía, y Tú, Padre mío, ayudadme a no caer ni siquiera en malos pensamientos.

Tu indigna hija, tu esclava, tú nada se postra a vuestros pies.

${ }^{2}$ Dice «hacer» en lugar de «a ser». Este error se encuentra en otros lugares del manuscrito. 
Meditación. Sobre los beneficios de N.S. Jesucristo [III día]

I. Los padecimientos que tuvo que sufrir antes de morir.

II. Los pecados de todos los hombres los expió Él, y por último el Amor tan grande en la S. Eucaristía. Cuando Lucifer dijo que no se sometía y el Eterno Padre estaba lleno de pecados de los hombres, y nadie se iba a salvar porque las ofensas eran a un Dios infinito. Pero Jesucristo se ofreció a sacrificarse por nosotros, y se cargó con todos los pecados de los hombres. Los míos estaban ahí, y Jesucristo estaba viendo mis pecados. Tomó nuestra naturaleza y agonizó 33 días $^{3}$, [primero] en Nazaret, y por último en el Calvario. ¿Porque en Nazaret?, porque estaba viendo todos los padecimientos, todo lo que iba a sufrir, y ese Niño que lo vemos nacer, ya estaba sufriendo por sus ingratos hijos. Todos los pecados de los hombres cayeron sobre su corazón. Podemos contar sus llagas del cuerpo, pero las del corazón, nunca, porque todos los pecados de los hombres cada uno le iba hacer una llaga, la que nunca se acabará. ¡Oh Jesús!, yo te [he] abierto muchas [llagas], pero ya no te quiero abrir más. Y solas las palabras de Jesucristo prueban que era un Dios el que estaba sufriendo, y los padecimientos del cuerpo no le dolían tanto como la del corazón. Hasta que dijo: «Padre mío, ibo».

Pero en lo que más nos manifestó su amor fue en el S. Sacramento, pues se quedó con el ingrato amado que no reconoce los sufrimientos de su Salvador y lo ultraja en su misma casa. Él se queda para consolar a otros.

Y, por último, nos da su Corazón, ese Corazón que tanto amó a los hombres. ¡Oh Jesús, Hermano mío!, toma mi corazón y tenlo con el tuyo, cosa que esté ahí para ayudarte y reparar los pecados de los hombres, y haz que nunca yo te ofenda.

Plática

Sobre la ciudad de Babilonia, madre de la corrupción. La corrupción es madre de todos los vicios. Una niña nunca se debe de dejar [llevar] por la sensualidad. Y cuando la alaben no hacer caso porque, [por] delante le están diciendo alabanza y, por detrás, criticándola. Una niña que es mundana busca todos los medios por ser alabada, viste muy elegante y cree que es muy bonita, y cree que tiene derecho para que todos la adoren y muchos la están criticando.

\section{Meditación}

Pongamos de ejemplo esa misma niña que todas alaban, pero las mujeres sencillas y los hombres no la alabarán, se reirán de ella. Respecto a Dios, ¿qué

\footnotetext{
${ }^{3}$ Se esperaría «33 años», pero el manuscrito dice «33 días».

${ }^{4}$ No es segura la transcripción. Si la expresión es ibo (iré), ella podría aludir a la voluntad del Hijo para ir a salvar el mundo. Cf. Ignacio de Loyola, EE 107.
} 
dirá?, que Él la crió para que lo amara y se sirviera de sus miembros para hacerlo conocer, y ella, todo lo contrario, se ama a sí misma. El diablo, ¿qué dirá?, estará contento porque verá que le quita la gloria a Dios y le da almas. Ya esta costumbre adquirida, no podrá salir ni aun cuando esté vieja porque entonces se mirará al espejo, como pasó con una. ¡Dios mío permite que nunca sea tan escandalosa!

\section{Sobre la perseverancia}

Como estos días se ha estado meditando tantas verdades y se han hecho propósitos, tenemos de alguna manera [que] ser siempre tan buenas. Para esto, debemos ser muy devotas del S. Corazón y del S. Sacramento, y también de la S. Virgen y del Patriarca S. José. Debemos decirle a nuestra Madre que nos guarde en su corazón y, ya que nos ha hecho meditar sus verdades, nos haga cumplir las resoluciones. Ser devotas de S. José porque la Iglesia lo ha declarado su Patrón, y también de la Juventud, y, en especial, abogado de la buena muerte.

\section{Cosas de conciencia ${ }^{5}$}

Mortificaciones. Martes 28 [de abril] de 1914. II Día de retiro en honor de mi Madre del cielo y mi Amor, Jesús.

Lunes: Me voy a fijar por amor a Jesús hacer toda clase de obediencia, procurar en este día no faltar a esta promesa con la ayuda de Jesús, María y José.

Martes: Todos los martes no voy a pelear con mis hermanos por amor a mi Madre.

Miércoles: Hoy, por amor a mi Padre S. José, voy a ser muy lista para levantarme.

Jueves: Hoy, por amor al Jesús Sacramentado, no voy a ser rabiosa.

Viernes: Hoy, por amor a mi Todo, no voy a ser orgullosa.

Sábado: Hoy, por amor a mi Madre, no voy a mentir ni por broma.

Domingo: Hoy, por amor a S. José, a Jesús, a mi Madre, no voy [a] hablar de pololeo y si me hablaran contestaré que no sé, y yo nunca hablaré de eso. ¡Oh mi Jesús, oh mi Hermano, oh mi Padre, oh mi Amor, oh mi Todo, haz que yo muera de amor por Ti!

¡Oh Virgen María, que título te daré en el que más te puedo demostrar mi cariño!, es en el de Madre mía. Haced, por favor, una sola cosa por mí, y es que sea humilde, pura y trabajadora, y que cumpla estas resoluciones.

\footnotetext{
${ }^{5}$ Este texto, contenido en la misma libreta, no es continuación de sus apuntes de retiro, sino un texto escrito con otra tinta, que debió de ser redactado después del retiro.
} 
¡Oh José mío!, ¿cómo quieres que te diga?, creo que te gustará el de Padre, y soy indigna porque sería hermana de mi Jesús e hija de María, y yo, tan pecadora, que sea hermana de la Perfección. ¡Oh Padre mío!, yo te pido que me hagas cumplir esta promesa. Y también, ¿no te parece, Padre mío, que cuando una hija tiene Hermano, Madre y Padre, que cuando se esté muriendo la socorran y la asistan y muera en sus brazos? ¡Oh, pues, Padre mío!, ruego que alcancéis de mi Hermano, Madre y Tu Padre mío, este favor.

Os entrego, Hermano, Madre mía, Padre mío, todo lo que tengo, lo que tendré, y después, cuando pase de este mundo inmundo, espero irme con vosotros. Cuando no haiga ${ }^{6}$ cumplido con las promesas que he hecho, me mortificaré, y si después me dan la fuerza, me azotaré con el permiso de mi confesor.

${ }^{6}$ Forma coloquial de «haya». 


\title{
NOTAS DEL RETIRO DE $1915^{7}$
}

Por el Rvd. Padre Blasco.

\section{AMDG}

\author{
Brevedad de la vida \\ El carro de la vida. \\ ¿Qué es la vida? \\ Una ilusión, una sombra, \\ una ficción en que el \\ mayor bien es pequeño. \\ Que toda la vida es sueño \\ Y los sueños, sueños son. \\ [Calderón de la Barca]
}

La vida es un sueño que todavía no principia cuando acaba. La vida es un tren expreso en el que pasamos el puente entre la cuna y tumba, y con estrepitosa y vertiginosa carrera. La vida es una ola que, tan pronto se forma como se pierde. En la juventud, la vida se ve bajo un prisma de cristal. Todos cuando llegamos a la edad de la razón tomamos un coche o, mejor dicho, cuando nacemos y cuando llegamos a los siete años, queremos correr, queremos volar, y tanto corremos y volamos, que llegamos al campo de las flores que vimos a los 15 años, pero cuando llegamos al campo, vemos otra cosa: las flores se han marchitado, las flores tienen espinas. Queremos volver, pero el cochero no quiere volver, los caballos se encabritan, se enredan en tantas espinas y caen en un abismo al llegar a la estación de la tumba.

¡He aquí la vida, no es una ilusión! «La ilusión es propia de las almas grandes». En la vida, las ilusiones que tenemos son de dos clases. Una que, cuando la vamos a tener realizada, es como una mariposa, que la vemos brillar, pero que al tocarla se deshace. La otra clase de ilusión es más noble, y la vemos realizada si no ponemos nuestras esperanzas en las primeras y es la ilusión de poder ir a gozar con Dios; y el único medio de ser feliz es la de poner nuestra confianza en ese Ser infinitamente misericordioso y servirlo como es debido. Esa es la ilusión que debemos tener siempre si queremos ser felices, buscarla en Dios. En la vida no hay felicidad posible porque es como un pedacito de nieve que muy luego se deshace. En la vida es todo «Vanidad de vanidades, y todo vanidad, y aflicción de espíritu». Dice Salomón que fue el que supo apreciar la vida [Qo 1,2].

\footnotetext{
${ }^{7}$ Libreta 6 (archivo del Monasterio de carmelitas descalzas del Espíritu Santo de Auco).
} 
Cosas necesarias para hacer bien el retiro.

I. Silencio exterior. II. Recogerse y entrar en sí misma. III. Conversar interiormente y escuchar lo que Jesús nos dice. Decir: «Hablad Señor que vuestra sierva escucha» [1Sam 3,10]. Y cuando golpee Jesús a las puertas de nuestros corazones, abridle. Preguntarse, ¿de dónde vengo y a dónde voy?

\section{Plática}

Fin del hombre: ¿Quién soy yo? -Soy un poco de polvo amasado con sangre. ¿De dónde vengo? -De Dios, Él me crió sin merecerlo. ¿Dónde voy? -A Dios.

El hombre cuando nace ve un monstruo con una guadaña que lo persigue, él arranca, pero no ve un precipicio, que hay un pozo con barro, y cae. Adentro ve un monstruo negro y otro blanco, y más adentro otro más con sus fauces abierto para tragarlo. Pero se alcanza a sujetar de un árbol, del cual caen unas gotitas de miel y ve el primer monstruo arriba del árbol que quiere quitarle las gotitas de esa miel. Yo soy [el] que arranco, caigo en el pantano, que son el pecado y el mundo, el monstruo blanco es el día que roe al árbol de la vida y el monstruo negro también y [el] monstruo grande es la eternidad. El monstruo que está con la guadaña es la muerte, la miel son las pocas gotas de felicidad en la tierra, y que la muerte no nos las deja saborear.

Nuestro fin. ¿Con qué fin Dios me puso en el mundo? ¿Porque me eligió entre tantas? Un gran fin se propuso Dios al criarnos, porque Dios nos dio todas las perfecciones de todas las creaturas. Dios nos crió para que lo adorásemos, lo sirviésemos como es debido. Me eligió entre tantas, porque, ¿qué hice yo? Nada, ¿y qué hago? Me rebelo contra Él y uso del de lo que Él me ha dado para ofenderlo.

¿Quién soy yo? Soy un poco de polvo y menos. Filosóficamente, soy un corcel y un caballero. El caballero es mi alma y el corcel el cuerpo. Mi alma debe manejar al cuerpo y no éste a ella. ¿De dónde vengo y dónde voy? Vengo de Dios, y voy a Dios.

\section{Meditación}

Valor del alma. Todo hombre se compone de dos cosas. Una de un valor infinito y otra que no vale nada. Nuestra alma tiene un valor infinito y nuestro cuerpo no sirve para nada. ¡De que nos servirá ganar el mundo entero si al fin perdemos nuestra alma! [Mt 16,26]. Nuestra alma fue hecha a semejanza de Dios. Ésta es, pues, la causa por qué Dios nos dio un fin, porque el cuerpo muere pero el alma, no. Nuestro cuerpo fue hecho para la tierra, porque tierra es y vive en un mundo inmundo, pero nuestra alma tiene un fin más noble, y no debe tener por patria a la tierra, no debe amar a lo que pasa, a lo caduco, 
sino que debe mirar por patria el cielo, y debe amar a Dios porque nuestra alma no muere, no se acaba. Dios quiere al alma con un amor infinito. El Padre nos dio a su Hijo. Éste se dio, y entregó hasta la última gota de su sangre, pero quiso darnos lo que más quería: nos dio a su Madre y Ésta nos dio a su Hijo y nos admitió como hijos a todos los pecadores. Todo esto vale nuestra alma, ¿y es posible que nos ocupemos más del cuerpo, de lo que muere y de lo que algún día ha de ser pasto de gusano, y no nos ocupemos más de lo que no acaba, de lo más grande que tenemos y que por la cual hemos de ser felices o desgraciado por toda la eternidad? Satanás estima nuestra alma. Cuando Jesucristo estuvo en el desierto y el demonio, no sabiendo quién era, lo tentó y le dijo que le daba todas las riquezas que quisiera y todo lo que abarcaba su vista, [imperio] por imperio, desde ese monte, le daba riquezas, imperios, porque Él lo adorase y así apropiarse su alma [cf. Mt 4,8-9]. Un alma, ¿cuánto vale? ¿De qué te servirá ganar el mundo entero si pierdes tu alma?

Orden natural. Dios nos pone las creaturas para que le amemos y le sirvamos, y nosotros nos servimos de ellas para ofenderlo.

\section{Meditación}

Sobre las dos cosas que nos impide nuestra santificación

Hay dos cosas que nos impiden nuestra santificación, el monstruo de la falta de indiferencia y el monstruo de la ingratitud. La falta de indiferencia para no hacer el mal, para lograr nuestro último fin, y la falta de indiferencia para hacer el bien. Luzbel perdió el cielo por no ser indiferente, no fue indiferente para servir a Dios bajo la naturaleza humana ${ }^{8}$. Eva y Adán, Caín, Herodes, Pilatos tuvieron falta de indiferencia para no hacer el mal. San Luis estaba indiferente para no hacer el mal y, aunque le costara lo que le costara, hacía el bien para lograr su último fin.

La ingratitud es el monstruo más grande que nos impide nuestra santificación. Unas bandas de bandidos asaltaban los caminos. El público quejase a la policía quien los persiguió sin poder alcanzar su paradero. Llegó un día que pillaron a 12. Fueron llevados a la ciudad, presos y condenados a morir. Al otro día se encaminaban los reos al lugar donde debían de acabar su vida. En una alameda fueron colgados de los árboles más grandes. Cuando todos se fueron, creyéndolos muertos, pasó un guerrero, un caballero que, sin saber lo que aquello contenía, vio que en un árbol algo se movía y vio que un hombre estaba con convulsiones. Toma su cuchillo y sube como puede, con grandes dificultades hasta arriba, toma al bandido con su mano izquierda y con la mano

\footnotetext{
${ }^{8}$ El texto no es claro, porque el término «falta» se puede comprender como la «carencia» de indiferencia o como el «pecado» de indiferencia.
} 
derecha corta la soga y baja, descansando a cada rato, por fin llega abajo, saca de su alforja una bebida que hace volver en sí al enfermo y lo sube a su corcel y arranca con él a un bosque, y en una posada baja al enfermo y dice a la posadera que haga venir a un médico, que él le pagará muy bien. A los pocos días el enfermo se principia a mejorar y el soldado paga la cuenta al deudor, y el bandido ve relucir en esa cartera mucho oro, le dan ganas de apoderarse de eso, pero ¡cómo va a pagar a su liberador de esa manera! El soldado dice que es preciso marchar, porque la policía puede perseguirlo. Toma al bandido lo sube al anca del corcel y huye. En el bosque, el bandido se acuerda del oro y ahí está solo, nadie lo ve, y sacando de su cinto el cuchillo, lo entierra en el corazón de su liberador. Toma el corcel y huye con todo. Fue monstruo de ingratitud. ¿Nosotros acaso no hacemos lo mismo con Cristo?

\section{II día. I Meditación}

Dios odia el pecado. Una de las perfecciones que en nuestra pobre naturaleza admiramos en Dios es la santidad, aunque todas sus perfecciones son infinitas.

Malicia y fealdad del pecado. El pecado hasta por los paganos es aborrecido. Aristóteles, no conociendo nuestra religión, no conociendo a Jesús en el Gólgota, prefiere morir antes de cometer un pecado ${ }^{9}$. Demóstenes y Alfir, niña hermosa, prefiere deslucir su cara para no ser causa de pecado a nadie y no cometerlo ella ${ }^{10}$. Hemos mirado a los paganos, al otro lado del Gólgota, miremos ahora después a este lado. Santa Brígida, mujer bonita, pide a Jesús ante el altar que borre su cara con granos para no ser tentación de pecado. Hasta en los mismos animales, en cierto modo, aborrecen el pecado. El armiño, cuando se ve perseguido, huye, pero si encuentra a su paso un pantano prefiere morir antes que pasarlo. Prefiere morir antes de perder su blancura.

Efectos del pecado. Los ángeles en el cielo pecaron. Llego un día en que Dios, aburrido con los pecados de los hombres, los iba a castigar. Mas Jesucristo, la segunda Persona, dijo: «Padre, Yo me haré hombre y, si es posible, moriré por ellos con tal que se salven». ¡Dios quiso probar a sus ángeles, a ver ${ }^{11}$ si se sometían adorar a Aquel que debía hacerse hombre! Y una cantidad: «iNo servimos a un Hombre!». Y en el mismo instante cayeron al infierno y quedaron convertidos en demonios, con su caudillo Luzbel.

Crió Dios al hombre y le dio para su residencia un magnífico palacio. Tenía un jardín, lo más hermoso que puede caber, pero Dios quiso poner a la prueba

\footnotetext{
${ }^{9}$ Es posible que este ejemplo, en realidad, aluda a Sócrates, destacado como ejemplo por la tradición cristiana.

${ }^{10}$ La transcripción del nombre de la niña hermosa es conjetural.

${ }^{11}$ Dice «haber» en lugar de «a ver».
} 
al hombre y le prohibió comer de un fruto del árbol del bien y del mal. Pero Eva comió y le dio a Adán, tentado por la serpiente infernal. Inmediatamente vinieron el hambre, toda clase de enfermedades, miserias, guerras y la muerte, y todos los males. Todo por un pecado.

Caminemos y veremos otra víctima de ese monstruo de pecado, echemos una mirada y veremos a Jesús, a Dios, en una Cruz, a la Santidad, a la Omnipotencia, convertido en oprobio, ¿y por qué está ahí? Por los pecados. No tiene en su cuerpo parte buena. ¡Oh monstruo de pecado, por ti vino la desgracia al mundo y por ti murió Jesús en el Gólgota!

\section{Plática}

El que desprecia las cosas pequeñas, poco a poco, caerá en las grandes. Si al principio no se cuida de un mal pequeño, podrá resultar uno grande y, capaz, hasta la muerte. Así lo mismo, si no se evitan las imperfecciones, caerá en pecados veniales, y si no se evitan éstos, caerán en pecados mortales. Hubo una familia en tiempo de Jesús, en su vida pública, muy amiga del divino Maestro. Era Marta y María. Una vez, Jesús recibe una carta diciéndole: «Maestro, Lázaro languidece, ven pronto». Jesús no va. Otra vez recibe otro billete: «Maestro, Lázaro ha enfermado». Recibe otro en que le dice: «Maestro, el que tú amas ha muerto». Jesús se encamina a verlo, y recibe otro: «Maestro, ya es inútil que vengas, porque Lázaro hace cuatro días que está muerto. Si tú hubieras venido, no hubiera muerto». Jesús se encamina al sepulcro y dice: «Levantad la losa que lo tapa». «Maestro - dice Marta- ya hiede». Aquí están los cuatro estados de oración: «languidece» es la imperfección, «enferma», pecado venial, «muere», pecado mortal, «hiede» es cuando se permanece en el abismo del pecado mortal y estamos próximo a irnos al infierno. El no seguir las inspiraciones puede tener graves consecuencias como el debilitamiento en el bien.

\section{Meditación}

El gran imperio de la muerte.

Es el más extenso después del de Dios. Con la muerte nadie puede pelear porque será vencido. Es la tumba una de las tres concupiscencias y de la impasibilidad del cadáver. Uno de los medios para proceder con santidad es el recuerdo de la muerte. Filipo, el gran rey, padre de uno de los mayores conquistadores, Alejandro, pagaba a un niño para que le recordara tres veces al día: «Filipo, acuérdate que tienes que morir». Maximiliano tenía dos magníficas carrozas, pero una era el doble mejor que la otra. En la peor iba él, ¿y a quién mandaría en la otra? La otra llevaba un cajón, un ataúd. Mariana de Jesús mandó hacer un retrato al pintor más famoso y le dijo [que] hiciera una niña lo más hermosa que pudiera idearse en su mente, pero nada más que al lado derecho, y al izquierdo pintara una calavera. San Francisco de Borja, cuando 
abrieron el cajón de Isabel, fue el único que quedó contemplándola. Todos retrocedieron, porque ya hedía. Entonces se convirtió, murió su esposa y se metió a la compañía de Jesús, y dijo: «No más servir a señores que puedan acabarse, morirse, sólo Dios no se muda».

La muerte del justo y del pecador. El justo espera la muerte, y se siente feliz cuando llega, porque sabe que es la feliz mensajera que lo ha de llevar a la eterna felicidad. El pecador, por el contrario, tiembla cuando llega y la quiere hacer esperar, pero ella no espera y tiembla porque sabe dónde irá. Mirarnos en el espejo de la muerte, que es [el] que no engaña, y también en María, ser igual a Ella. 


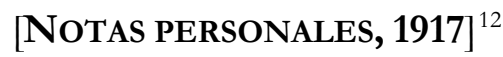

\author{
8 de Marzo de 1917
}

[Pensamientos sueltos] $]^{13}$

Es preciso sufrir hasta morir, es preciso morir sufriendo. Sufrir, amar y vivir. Empezar siempre con energía cada día, pues este corto espacio nos vale una eternidad feliz.

¡Qué son 24 años de sufrimiento!, son una gota de agua comparada con el océano.

Ser humilde es callar, es sufrir, es aceptar, es obedecer, es ser pura, es ser alegre en todas las circunstancias de la vida.

«Laudem gloriae ejus», consumirse, no haciendo nuestra voluntad, sino la de Dios a cada instante, pues esta es la vida del alma.

El amor es la fusión de dos almas, la identificación de dos seres que formarán uno sólo.

El ser que sufre y ama solo puede llegar [al] amor cuando encuentre otra alma que comparta sus dolores, entonces ya no existe ningún otro ser que pueda ser obstáculo para la total unión. Sufrir con Él, ¿no es vivir?

\footnotetext{
${ }^{12}$ Libreta 4 (archivo del Monasterio de carmelitas descalzas del Espíritu Santo de Auco). Esta libreta contiene una mezcla de textos, números, elencos de nombres y listas de compras. Sólo contiene dos textos continuos. El primero se omite, porque parece ser un resumen, no muy bien logrado, de alguna conferencia o de algún libro de apologética. Varias páginas después, hay una alusión a una obra apologética de Jaume Balmes, que podría ser la fuente.

${ }^{13}$ Este breve escrito tiene la escritura característica de santa Teresa de los Andes, pero parece que el título está escrito por otra mano.
} 


\section{Preparación Para la Comunión [1917 $]^{14}$}

Juana Fernández [Rebeca Fernández ${ }^{15}$ ]

\section{Preparación para la comunión}

Para antes de la Comunión

Humildad. Señor vengo a Ti porque soy muy pobre, estoy muy enferma por el pecado, y necesito de Ti, que eres el Todopoderoso y el Médico misericordioso. ¡Oh Jesús mío, me confundo al ver tu infinita grandeza y mi extremada miseria!, mas tú eres mi Vida, sin Ti nada soy, nada tengo, venid pues a la pobre casa de mi alma, que aunque es muy pequeña para contenerte, Tú, Señor Todopoderoso, te empequeñeces, te anonadas para entrar en ella. Mas te llamo a ti, Dios infinito, Dios eterno, sin principio ni fin, a Ti, Dios Todopoderoso, que con una sola palabra creadora has sacado los cielos y la tierra de la nada. Tú, que has creado los océanos llenos de infinitas riquezas de majestad y belleza. Tú, que creaste la tierra tan hermosa para que viviera el hombre en el destierro, las montañas con sus cimas de blanca nieve, los astros suspendidos en el magnífico firmamento; Tú, Señor, creador del hombre, creatura la más perfecta de la tierra, dándole una inteligencia capaz de conocerte y una voluntad para amarte. Tú, Creador del cielo, paraíso de los escogidos. Tú Señor de los ángeles, vas a entrar en mi estrecho y ruin corazón. Tú, el Jehová, delante del cual los tronos y las dominaciones tiemblan, los serafines quedan extasiados, los ángeles se ocultan con sus alas, llenos de temor ante tu infinita majestad, mientras yo, pobre pecadora, te convido a unirte a mí. Tú, el Santo. Tú, el Inmenso, más grande que todo cuanto creaste, vas a entrar a la pobre casa de mi alma. Señor, yo no soy digna. Mas Tú, Dios mío, Tú, Dios de amor, vienes a mí, bajas del cielo a la tierra a tomar nuestra miserable humanidad. ¡Mientras quiere el hombre ser dios, Tú quieres ser hombre! ¡Oh Amor de un Dios humanado!, que te destierra al valle de miseria para condolerte de nuestras lágrimas, para ser el sostén de nuestras almas desfallecidas y el refugio de las desamparadas. Con todo, no te basta morir para resucitarnos a la vida de la gracia, quieres más humillación, más calvario. ¡Loco de amor te conviertes en Pan, oh Jehová! Tú, el Dios terrible de otros tiempos hoy te presentas bajo la forma del Pan para servir de alimento a nuestras almas. Tú, Pan para penetrar al santuario íntimo de nuestro corazón, reducto donde se hallan las miserias

14 Libreta 7 (archivo del Monasterio de carmelitas descalzas del Espíritu Santo de Auco). Apuntes 1917 (colegio y casa).

15 El nombre de Rebeca Fernández está puesta por una mano diferente a la del resto de la libreta, lo que sugiere que es posterior. Posiblemente, Rebeca utilizó esta libreta de su hermana mayor. Algunos giros típicos, tales como «nada criminal», «Loco de amor», «hostia de amon», etc., confirman que este escrito es de Juana Fernández. 
más grandes, órgano donde se hallan las enfermedades más repugnantes. Tú, Dios mío, Tú, ¿Pan? El Eterno, el Todopoderoso, convertido en hostia por amor a unas creaturas que no hacen más que olvidarlo despreciarlo, ofenderlo, vivir en desenfrenada alegría, mientras Jesús agoniza en el Sagrario por amarlos. Tú, Señor, Pan, y no en un punto de la tierra, sino en todos los tabernáculos del mundo; una reliquia tuya sería demasiado para creaturas tan indignas, pero quedarte Tú mismo, iy bajo la apariencia de Pan! Todo es poco para Tu amor infinito, desapareces completamente para entrar en nuestras almas; después de recibirte, solo se ve la nada criminal. Sí, Jesús, yo soy nada criminal, y por amarme, Tú desapareces, te haces nada criminal.

Amor. Señor, ¿cómo no amarte? ¿Cómo no llorar ante tu infinito Amor? Si Tú, por acercarte a mí, te anonadas, ¿cómo huir de Ti, Dios infinito? Vengo, ¡oh Amor!, a recibirte, tu amor me ha vencido, mas antes te pido perdón de mis ofensas. Señor, muchas veces no he sido fiel a tus inspiraciones, me has dado, divino Cordero, balidos de amor, y no te he respondido; muchas veces, Tú has llorado por mí y no te he consolado, perdóname joh Dios de amor! Madre mía dadme a mi Amor, pero antes prepara esta pobre morada.

\section{Después de la comunión}

Amor y adoración. Señor te estrecho contra mi corazón, un Dios unido a su creatura, joh Amor infinito, me anonado en tu presencia! Jesús mío, me pongo a tus pies como la Magdalena, riego tus pies con mis lágrimas, jJesús, soy una pecadora, pero te amo! La nada con el Ser por excelencia, la Santidad con el pecado, el Infinito con la muerte, el Todopoderoso con la impotencia ¡Señor, cómo no amarte, lloro porque después de tanto amor, tanto te ofendo! Señor, tú ves la pobreza de mi morada, mas aunque sea así, te la doy, ella ha de servirte para esconderte de tus enemigos, quédate Jesús en ella, para vivir a Ti unida. Es cierto que soy mala, pues me has llenado de favores y, sin embargo, no soy santa; mas, si Tú no estás conmigo, seré peor, pues eres Tú mi fortaleza y mi Vida. Señor, yo te adoro y te doy gracias por haber venido a mí. No tengo como expresarte mi reconocimiento porque soy muy miserable, mas te ofrezco ese Amor eterno con que Tú, Padre, y Tú, Verbo divino, te amas. Sí, te ofrezco el Espíritu Santo, te ofrezco el amor de la Santísima Virgen, el de los ángeles y serafines y el de toda la corte celestial; te ofrezco el amor de las almas del purgatorio, el de los justos de la tierra, y te ofrezco mi pobre amor. Señor, ensancha más en mí la capacidad de amarte, pues anhelo amarte con infinito amor. ¡Oh, mi Dios, Tú estás en mí! ¡Oh Trinidad beatísima!, yo te adoro y te contemplo unida a mí, yo me anonado delante de Ti, Dios mío. Tú, grandeza infinita, belleza que cautivas mi corazón. Me arrojo en tu atmósfera divina de amor, quiero vivir adorándote con los ángeles del cielo y diciendo siempre: 
¡Santo, Santo, Señor Dios de los ejércitos!, etc.; quiero repetir con mi Madre Santísima, ¿De dónde a mí tanta dicha, que el mismo Dios me venga a visitar? [Lc 1,43]. Señor, yo te amo y te doy gracias. Dame, joh Padre!, tu Amor, Luz, Sabiduría; Tú, Verbo adorado, dame Cruz, cáliz, espinas; Tú, Espíritu de Amor, dame amor luz, santidad.

Conversación. Jesús mío aquí está tu amiga, háblame con intimidad; me apoyo sobre tus rodillas, te abrazo, y me recuesto sobre tu corazón, siento tus latidos, ¿qué tienes, Jesús querido, que veo sobre tus ojos de cielo algunas lágrimas?, ¿tienes pena? Cuéntame por qué estás triste... Señor, no quiero verte así coronado, ponme tu corona. Yo quiero sufrir contigo. ¿Qué quieres hoy de mí?... Ayúdame a serte fiel, te doy mi voluntad, haz que cumpla la tuya, Amor mío. Llama a mi Madre María para que nos vea así unidos, quiero también hacer algo por su amor... Jesús, te amo, Madre mía dadme Jesús, haz que viva hoy unida a Él, de manera que cuando las creaturas me llamen, responda y obedezca a Jesús y en todo vea sólo a Él. Petición y oración. 


\section{[Poco antes de irse al Carmen, 1919] ${ }^{16}$}

Sacrificarse, inmolarse la vida entera porque amamos ¿No se sacrificó Él por nosotros? ¿No sufrió su vida entera? ¿No fue pobre desde Belén hasta el Calvario? Somos suyas, donde Él esté, debemos estar con Él, en Belén, en la Cruz, en la pobreza, para estar después con Él una eternidad.

No lo busquemos en la tierra con los sentidos, busquémosle en la Eucaristía, en el cielo, con la fe, es quizás nuestra falta principal el querer sentir, pero acordémonos que Él es un Dios, y no creatura, no lo podemos palpar con nuestras manos, pero sí la razón lo conoce, sometamos el sentimiento, sacrifiquémoslo. Cincuenta, cien años aquí en la tierra, para gozar de Él eternamente, deleitándonos en su amor.

Pensemos que Él murió amándonos, y esa es su ocupación allá en el cielo. Mirémosle, Él nos ve, ve nuestras miserias y ve también nuestra voluntad de amarle siempre y de principiar aquí en la tierra lo que haremos por una eternidad. Si Él es infinitamente sabio e infinito en perfecciones, ha ideado ese amor es porque es lo más perfecto y lo más grande, luego si podemos amar desde aquí, ¿por qué no hacerlo? ¿En qué consiste el amor? En la fusión de dos almas. Fundámonos con Él en la Cruz, seamos puras, castidad, obedientes y pobres como Él lo es. ¿Y dónde se sufre más, se es más pura, más obediente y más pobre, que en donde Él?

\footnotetext{
16 Un breve documento sin número contiene este escrito de Teresa de los Andes (archivo del Monasterio de carmelitas descalzas del Espíritu Santo de Auco). Al final de él, Elisa Valdés anotó: «Esto lo escribió la Juanita Fernández pocos días antes de irse al Carmen, en un momento de expansión».
} 


\section{[EXAMEN DE CONCIENCIA 1919-1920] ${ }^{17}$}

Método para el examen de conciencia

1. Ponerse en presencia del Señor con humildad.

2. Reconocer las faltas.

3. Considerar los beneficios que Dios N.S. nos ha hecho en el día.

4. Comparación entre las faltas y beneficios.

5. Afectos - contrición.

6. Hacer nuevos propósitos.

7. Proponer y dar desde luego satisfacción rezando algo o haciendo después alguna mortificación o penitencia.

8. Pedir perdón, con el real Profeta, de los pecados ocultos «Ab occultis meis munda me» [Sal 18,13] y

9. Pedir perdón de las faltas ajenas, «et ab alienis parce servo tuo» [Sal 18,14], es decir, de aquellos pecados cometidos por causa de modestia.

El examen hecho de esta manera procura los beneficios de la confesión sacramental porque purifica nuestra alma y la acerca a Dios más y más. Por lo que no debemos omitirlo nunca y si no se hace en el coro, hacerlo en particular en el momento que se pueda.

En las materias de examen pueden seguirse dos métodos:

1. Nuestros deberes para con Dios, nuestro prójimo y nosotras mismas.

2. Si se ha practicado la mortificación. Si se han ejercitado las virtudes y se han hecho los ejercicios o prácticas espirituales, es decir: la oración, el rezo del Oficio Divino, asistencia puntual a los actos de comunidad, etc., etc.

Examen

1. ¿He dado mi corazón a Dios al despertarme?

2. ¿He sido pronta al levantarme y modesta al vestirme?

3. ¿He asistido al coro, a la misa y al Oficio Divino, poniendo en ella atención y devoción?

4. ¿Me preparado con esmero para recibir los sacramentos?

5. ¿He guardado el retiro de la celda?

6. ¿He hablado sin voz en los lugares determinados?

${ }^{17}$ Libreta 1 (archivo del Monasterio de carmelitas descalzas del Espíritu Santo de Auco). 
7. ¿Me he aplicado como debiera a la labor particular y obligaciones del oficio con intención de agradar a Dios?

8. ¿He perdido el tiempo? ¿He procurado aprovecharlo bien?

9. ¿He faltado a la observancia?, ¿a la puntualidad?

10. ¿He cumplido con las órdenes de la obediencia?

11. ¿He sido respetuosa y atenta con mis Superiores y las Hermanas?

12. ¿He descuidado en algún punto la pobreza?

13. ¿He velado sobre mis pensamientos y afectos?

14. ¿Cómo he practicado la humildad y sencillez?

15. ¿He faltado a la caridad en pensamiento las palabras ni obras?

16. ¿He faltado a la modestia de la vista? En el coro y en los claustros ¿procuro tener la vista sujeta?

En las recreaciones

17. ¿He manifestado igualdad de amor y deferencia para todas?

18. ¿He hablado de cosas o personas del mundo sin objeto, inútilmente? ¿Al procurar agradar he tenido motivo de amor propio o vanidad?

En el refectorio

19. Al comer che procurado sobrenaturalizar el acto, haciéndolo en el nombre del Señor?

20. ¿He dejado de comer porque me desagrada?

21. ¿He cumplido con las mortificaciones propuestas?

22. ¿He guardado la modestia de la vista y compostura religiosa, la moderación?

23. En las tomas de culpas y capítulos, ¿me penetro de las advertencias para corregirme?

25 ¿He hablado de mí misma sin necesidad?

26. ¿He mirado en mis hermanas a Jesucristo?

27. ¿Mi presencia de Dios ha sido continua?

28. ¿He hablado inútilmente fuera del recreo?

29. ¿Me he renunciado en lo que Jesús me pide?

Medios para alcanzar la virtud en ejercicio

1. Armarse de una consideración de los bienes que trae la virtud en su ejercicio (al despertar).

2. Pedirla al Señor en la comunión y oración. 
3. Hacer actos interiores y exteriores.

4. Procurar aumentar los deseos de adquirirla.

5. Imponerse penitencia por las faltas.

6. Hacer dos veces al día el examen particular.

7. Hacer comparaciones de las faltas cometidas de un día con otro, y de los actos ejercitados; pidiendo a Dios N.S. perdón por las faltas; y dar las gracias atribuyendo a Él todo el buen éxito del examen.

Oh Jesús crucificadme, pero dadme tu heroísmo divino, que sufra en silencio sin que las creaturas se aperciban, crucificadme en todo momento, y de todos modos, y que en nada encuentre gusto ni satisfacción, que por doquiera que vaya encuentra la Cruz. Oh Jesús querido, asemejadme cada vez más a Vos, que cumpla en todos los instantes de mi vida tu adorable voluntad.

Mi alma, Jesús, sufro pero deseo sufrir más, contemplo mi impotencia, mi anonadamiento, pero a pesar que me siento por Vos rechazada que me dices que no te amo, me abandono en tu divino Corazón, de allí no me puedes arrojar, es mi asilo, tú me lo diste así pues ama cuando sus miradas están llenas de enojo para tu pobre nada criminal, tu Corazón no sabe sino latir lleno de ternura para ella. Oh jamás dejaras de ser Jesús; perdóname que tu amor no haya conseguido romper los hilos de mi pobre corazón.

[Horario de Ejercicios espirituales]

Misa

[Tiempo libre]

Meditación

[Tiempo libre]

Plática

Comida

[Tiempo libre]

El mes

Siesta

Víspera

Lectura

Plática

[Tiempo libre]

Oración

Cena

[Tiempo libre]

Visita

Completas

\section{$71 / 4-8$}

$8-81 / 2$

$8 \frac{1}{2} 9^{1 / 2}$

9 $1 / 210$

10 a $11-5$

$11 \frac{1 / 2}{2}$

$11^{1 / 2} 12^{1 / 2}$

$12 \frac{1 / 2}{2}-1$

1- 2

$2-2 \frac{1}{2}$

$3-4$

$4-43 / 4$

$5-6$

$6-6^{1 / 2}$

$61 / 2-71 / 2$

$71 / 2-73 / 4$ 